\title{
Pengaruh Kualitas Pelayanan Terhadap Citra Rumah Sakit Umum Dr. Ferdinan Lumban Tobing Kota Sibolga Tahun 2019
}

\author{
Muhammad Mahadi Hasibuan, Arifah Devi Fitriani, Deli Theo \\ Institut Kesehatan Helvetia Medan \\ 123mahadi@gmail.com
}

\begin{abstract}
ABSTRAK
Citra Rumah Sakit sangat bergantung pada persepsi pasien atas kualitas pelayanan yang diberikan. Citra menjadi pembeda antara satu Rumah Sakit dengan Rumah Sakit lainnya. RSU dr. Ferdinand Lumbantobing merupakan Rumah Sakit milik Pemerintah Kota Sibolga dengan Tipe B dan terakreditasi Paripurna. Sebagai Rumah Sakit Rujukan RSU Ferdinand Lumbantobing memiliki tingkat kepercayaan masyarakt yang rendah, hal ini dilihat dari tinkgat Bed Occupancy Ratio yang rerata di tahun 2016-2019 hanya berada di angka 32,5\%. Jenis penelitian ini adalah explanatory research (penelitian penjelasan) dengan menggunakan pendekatan kuantitatif desain cross sectional. Populasi dalam penelitian ini adalah seluruh pasien rumah sakit yang menjalani rawat inap pada bulan juni 2019 di RSU dr. Ferdinand Lumbantobing Kota Sibolga yang berjumlah sebanyak 345 pasien. Metode analisis data dalam penelitian ini adalah dengan menggunakan analisis regresi logistik. Hasil analisis multivariat menunjukkan bahwa dari 4 variabel independen yang dianalisis, variabel profesi $(p=0,001)$, efisiensi dan efektifitas $(p=0,003)$, keselamatan pasien $(p=0,001)$, dan kepuasan pasien $(p=0,012)$ yang berpengaruh secara signifikan terhadap citra RSU dr. Ferdinand Lumbantobing Kota Sibolga. Kesimpulan dari penelitian ini terdapat pengaruh antara variabel independen (profesi, Efisiensi \& Efektifitas, keselamatan pasien dan kepuasan pasien) terhadap variabel dependen ( citra rumah sakit).Disarankan bagi manajemen RSU dr. Ferdinand Lumbantobing Kota Sibolga perlu memberikan perhatian mendalam pada beberapa unsur kualitas pelayanan, Khususnya pelayanan administrasi, pelayanan klinis, IGD dan mengadakan pembaharuan dan penambahan sarana dan prasarana.
\end{abstract}

Kata Kunci: Kualitas Pelayanan, Citra Rumah Sakit, Rumah Sakit

\section{ABSTRACT}

The Image of the hospital is dependent on the patient's perception of the quality of services provided. Hospital image is important to differentiate between one hospital and another. dr. Ferdinand Lumbantobing Hospital is a hospital-owned by Sibolga Local Government with type $B$ and fully accredited. As a referral hospital, dr. Ferdinand Lumbantobing has a low level of public confidence, this can be seen from the bed occupancy ratio which averaged only 32.5\% in 2016-2019. This research was explanatory research using a quantitative approach with a cross-sectional design. The population of this study were all patients who were hospitalized in June 2019 at dr. Ferdinand Lumbantobing Hospital in Sibolga, totalling 345 patients. The method of data analysis in this study used logistic regression analysis. The results of multivariate analysis showed that of the 4 independent variables analyzed, namely profession $(p=.001)$, efficiency and effectiveness $(p=.003)$, patient safety $(p=.001)$, and patient satisfaction ( $p=.012$ ) had a significant effect on image of dr. Ferdinand Lumbantobing Hospital, Sibolga. The conclusion of this study is that there is the influence between the independent variables (profession, efficiency and effectiveness, patient safety, and patient satisfaction) on the dependent variable (hospital image). It is recommended for dr. Ferdinand Lumbantobing Hospital, Sibolga needs to pay deep attention to several elements of service quality, especially administrative services, clinical services, emergency departments and conducting renewals and additions of facilities and infrastructure.

Keywords: Service Quality, Hospital Image, Hospital 


\section{PENDAHULUAN}

Citra Rumah Sakit sangat bergantung pada persepsi pasien atas kualitas pelayanan yang diberikan. Citra menjadi pembeda antara satu Rumah Sakit dengan Rumah Sakit lainnya. Sehingga, dalam memahami dan mengelola hubungan antara citra Rumah Sakit dan intensi pasien rawat inap sangat diperlukan mengingat pengalaman pasien rawat inap akan lebih melekat pada persepsi pasien terhadap Rumah Sakit tersebut. Rumah Sakit dengan citra positif yang melekat padanya dimata pasien, relatif memiliki produk yang lebih bisa diterima oleh pasien. Di lain pihak, citra positif juga dapat mempengaruhi perasaan karyawan. Dimana karyawan akan merasa bangga bila bekerja di perusahaan yang memiliki nama baik. Sehingga, karyawan semakin termotivasi untuk meningkatkan kinerjanya, lebih produktif, dan berusaha melayani pelanggan dengan service excellent (1).

Dalam upaya menghasilkan citra yang positif secara berkelanjutan, orientasi Rumah Sakit perlu mengarah pada pasien yang pada dasarnya merupakan pembeli jasa pelayanan. Salah satu kuncinya ialah berusaha memenuhi kebutuhan kesehatan pasien sehingga pasien merasa puas dan gembira dengan pengalaman dirawat di Rumah Sakit tersebut. Kepuasan merupakan suatu penilaian atau bentuk dari persepsi pasien yang menyatakan bahwa suatu layanan telah memberikan tingkat kenikmatan yang sesuai dengan harapan bahkan lebih dari yang diharapkan. Maksud dari tingkat kenikmatan adalah suatu kesesuaian antara kualitas layanan yang dirasakan dari pengalaman menggunakan jasa dengan apa yang diharapkan (1).

Kepuasan pasien menjadi dasar penentu baik tidaknya citra suatu Rumah Sakit. Jika pasien merasa puas dengan kinerja pelayanan Rumah Sakit maka akan terbentuknya sebuah kepuasan pasien. Kepuasan dari pasien akan mendorong pasien datang kembali untuk berobat maupun berkepentingan kepada Rumah Sakit tersebut. Begitupun sebaliknya pasien yang tidak terpuaskan akan meninggalkan dan bahkan tidak akan merekomendasikan kepada yang lain. Karena pada dasarnya pasien hanyalah seseorang yang menerima hasil dari kinerja dan pelayanan dari suatu organisasi maupun instansi, maka hanya merekalah yang bisa mengetahui, merasakan dan menentukan (2).

Penilaian kualitas pelayanan yang banyak mendapatkan perhatian adalah yang lebih dikenal SERVQUAL, yang dikemukan oleh Parasuraman, Zeithami dan Berry yang mendefinisikan sekumpulan atribut-atribut pelayanan secara lengkap di mana para pasien menggunakan sebagai kriteria dalam menilai kinerja pelayanan. Penilaian yang dilakukan terhadap kualitas pelayanan tercakup dalam lima dimensi pelayanan yaitu bukti fisik (tangibles), kehandalan (reliability), daya tanggap (responsiveness), jaminan (assurance) dan empati (empathy) (3).

Kualitas pelayanan dapat diketahui dengan cara membandingkan persepsi para penerima layanan atas layanan yang benarbenar mereka terima. Kualitas pelayanan sebagai metode untuk mengukur mutu pelayanan, artinya apakah pelayan- an yang dilaksanakan di sebuah organisasi tersebut memberikan kepuasan pada pemakai. Pelayanan yang diberikan dievaluasi apakah memberikan kepuasan para pengguna. Pelaksanaan pelayanan yang bermutu sangat penting dalam era persaingan ini. Semakin tinggi mutu pelayanan yang dilaksanakan, semakin banyak pula penerima layanan terpuaskan (4).

Berdasarkan tingkat BOR sejak tiga tahun terakhir rata-rata angka bor berada pada 36\%. Jika dirincikan pada tahun 2016 angka BOR hanya 35\%, tahun 2017 naik sedikit menjadi 37\%, dan di tahun 2018 angka stabil di 27\%. Angka ini masih jauh dari indikator kinerja Rumah Sakit yang telah ditetapkan oleh Dapertemen Kesehatan tahun 2005 yaitu sekitar $80-85 \%$. Rendahnya pemanfaatan RSU dr. Ferdinand Lumban Tobing Sibolga diasumsikan akibat dari persepsi masyarakat yang menilai kualitas pelayanan RSU $d r$. Ferdinand Lumban Tobing Sibolga masih kurang baik.

Berdasarkan hasil wawancara yang telah dilakukan terhadap 20 pasien terkait kualitas pelayanan RSU dr. Ferdinand Lumban Tobing Sibolga, menunjukkan beberapa pasien menilai kualitas pelayanan di Rumah Sakit tersebut masih belum dapat dikatakan baik. 
Beberapa pasien mengangap peralatanperalatan medis yang dibutuhkan oleh pasien kurang lengkap, tenaga medis yang tidak menerangkan tindakan yang akan dilakukan, dan perawat yang dinilai tidak cekatan serta kurang menghargai pasien seperti perawat tidak mau menjelaskan secara lengkap mengenai cara perawatan dan minum obat kepada pasien.

Hasil penelitian Marzaweny menunjukkan bahwa kualitas pelayanan kesehatan memiliki pengaruh yang positif dan signifikan terhadap kepuasan pasien dan citra rumah sakit. Kepuasan pasien juga memiliki pengaruh yang signifikan terhadap citra Rumah Sakit. Oleh sebab itu, kepuasan pasien dipandang memiliki peranan dalam memediasi hubungan antara kualitas pelayanan kesehatan dan citra RSUArifin Achmad Pekanbaru (5). Sama halnya dengan Sharon yang menunjukkan bahwa kualitas pelayanan berpengaruh positif terhadap citra rumah sakit, selain itu kualitas pelayanan berpengaruh terhadap kepuasan pasien, dan juga loyalitas pasien (6).

Berdasarkan uraian latar belakang di atas maka dinilai perlu adanya pengkajian lebih dalam lagi mengenai "Pengaruh Kualitas
Pelayanan Terhadap Citra Rumah Sakit dengan Kepuasan Pasien Sebagai Variabel Intervening di Rumah Sakit Umu dr. Ferdinand Lumban Tobing Kota Sibolga Tahun 2019".

\section{METODE}

Jenis penelitian ini adalah explanatory research (penelitian penjelasan) dengan menggunakan pendekatan kuantitatif desain cross sectional (7). Penelitian ini dilakukan di RSU dr. Ferdinand Lumbantobing Sibolga yang dimulai sejak bulan Desember tahun 2018 hingga selesai. Populasi dalam penelitian ini adalah seluruh pasien rumah sakit yang menjalani rawat inap pada bulan juni 2019 di RSU dr. Ferdinand Lumbantobing Kota Sibolga yang berjumlah sebanyak 345 pasien. Analisis yang digunakan dalam penelitian ini terdiri atas analisi univariat bertujuan menjeleskan karakteristik setiap variabelnya dan disajikan dalam bentuk tabel, analisis bivariat bertujuan untuk melihat hubungan antar variabel dan dilakukan menggunakan uji Chi Square, dan analisis multivatiat dilakukan menggunakan uji Regresi Logistik (7) .

Tabel 1.

Distribusi Frekuensi Karakteristik Responden Berdasarkan Data Demografi

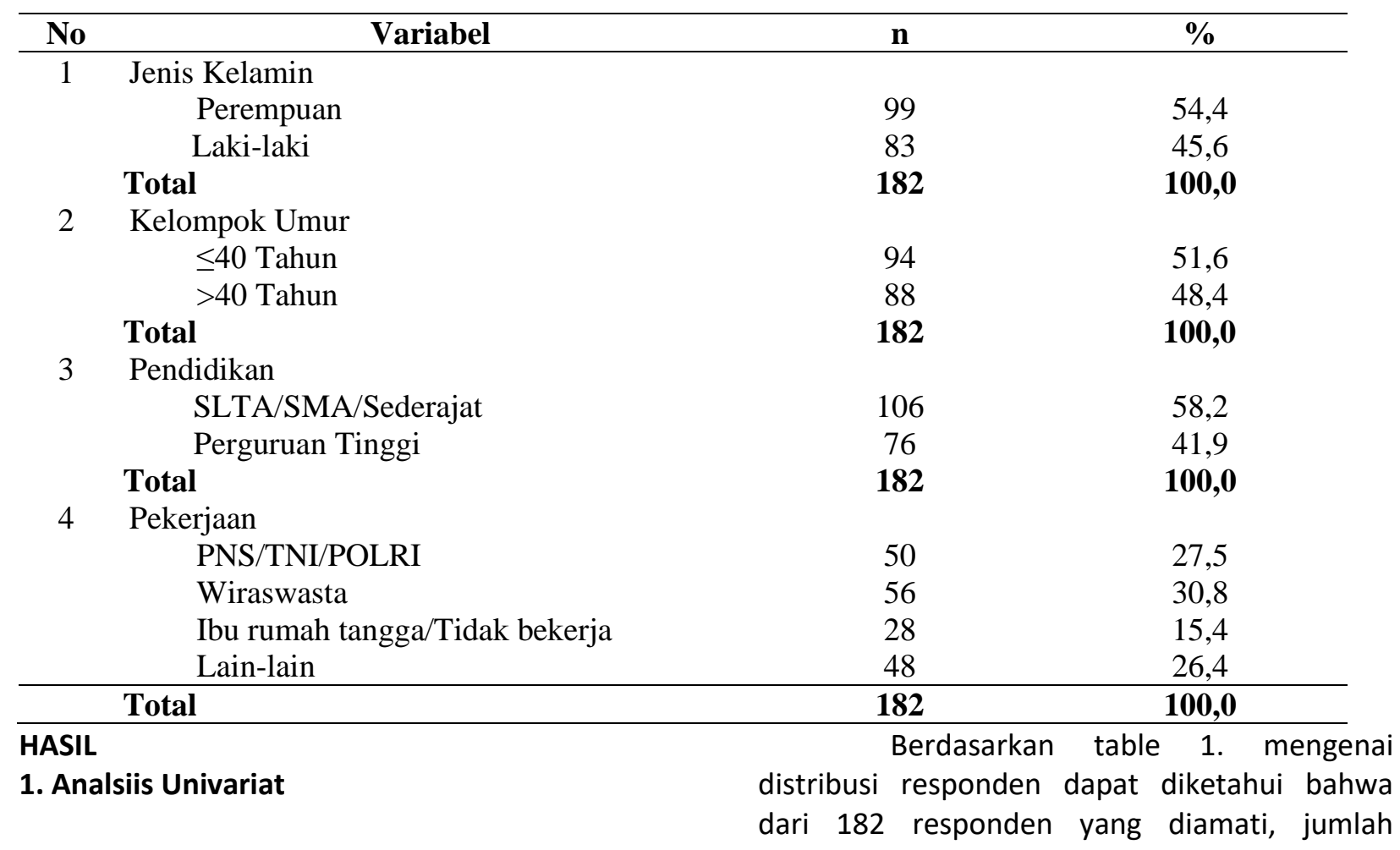

http://ejournal.urindo.ac.id/index.php/MARSI 
responden yang berjenis kelamin perempuan ada sebanyak 99 orang $(54,4 \%)$, dengan rentang umur $\leq 40$ tahun yaitu ada sebanyak 94 orang (51,6\%), pendidikan terakhir jenjang SMA yaitu ada sebanyak 106 orang $(58,2 \%)$, dan jenis pekerjaanya adalah wiraswasta yaitu ada sebanyak 56 orang $(30,8 \%)$.

Tabel 2.

Tabulasi Silang antara Variabel Kualitas Profesi dengan Citra RSU dr. Ferdinand Lumbantobing Kota Sibolga Tahun 2019

\begin{tabular}{|c|c|c|c|c|c|c|c|}
\hline \multirow{3}{*}{$\begin{array}{c}\text { Kualitas } \\
\text { Profesi }\end{array}$} & \multicolumn{4}{|c|}{ Citra Rumah Sakit } & \multirow{2}{*}{\multicolumn{2}{|c|}{ Total }} & \multirow{3}{*}{$\mathrm{p}$ value } \\
\hline & \multicolumn{2}{|c|}{ Baik } & \multicolumn{2}{|c|}{ Tidak Baik } & & & \\
\hline & $\mathrm{n}$ & $\%$ & $\mathrm{n}$ & $\%$ & $\mathrm{n}$ & $\%$ & \\
\hline Baik & 77 & 65,8 & 40 & 34,2 & 117 & 100,0 & \multirow{3}{*}{0,038} \\
\hline Tidak Baik & 33 & 50,8 & 32 & 49,2 & 65 & 100,0 & \\
\hline Total & 110 & 60,4 & 72 & 39,6 & 182 & 100,0 & \\
\hline
\end{tabular}

\section{Analisis Bivariat}

Berdasarkn tabel 2. dapat diketahui tabulasi silang antara variabel kualitas profesi dengan citra RSU dr. Ferdinand Lumbantobing Kota Sibolga, bahwa dari 182 responden yang diamati, terdapat sebanyak 117 orang yang menilai kualitas profesi baik dengan 77 orang $(65,8 \%)$ diantaranya menilai citra RSU dr. Ferdinand Lumbantobing Kota Sibolga baik, sedangkan 40 orang $(34,2 \%)$ sisanya menilai citra RSU dr. Ferdinand Lumbantobing Kota Sibolga tidak baik. 32 orang $(49,2 \%)$ diantaranya menilai citra RSU dr. Ferdinand Lumbantobing Kota Sibolga tidak baik, sedangkan 33 orang $(50,8 \%)$ lainnya menilai citra rumah sakit baik. Pada hasil analisis dengan chi square diperoleh nilai $p$ sebesar 0,038 $(p<\alpha)$, maka dapat disimpulkan bahwa terdapat hubungan yang signifikan antara variabel kualitas profesi dengan citra RSU dr. Ferdinand Lumbantobing Kota Sibolga Tahun 2019.

Tabel 3 .

Tabulasi Silang antara Variabel Kualitas Efisiensi dan Efektifitas dengan Citra RSU dr. Ferdinand Lumbantobing Kota Sibolga Tahun 2019

\begin{tabular}{|c|c|c|c|c|c|c|c|}
\hline \multirow{3}{*}{$\begin{array}{c}\text { Kualitas Efisiensi } \\
\text { dan Efektifitas }\end{array}$} & \multicolumn{4}{|c|}{ Citra Rumah Sakit } & \multirow{2}{*}{\multicolumn{2}{|c|}{ Total }} & \multirow{3}{*}{$\mathrm{p}$ value } \\
\hline & \multicolumn{2}{|c|}{ Baik } & \multicolumn{2}{|c|}{ Tidak Baik } & & & \\
\hline & $\mathrm{n}$ & $\%$ & $\mathrm{n}$ & $\%$ & $\mathrm{n}$ & $\%$ & \\
\hline Baik & 73 & 83,0 & 15 & 17,0 & 88 & 100,0 & \multirow{3}{*}{0,001} \\
\hline Tidak Baik & 37 & 39,4 & 57 & 60,6 & 94 & 100,0 & \\
\hline Total & 110 & 60,4 & 72 & 39,6 & 182 & 100,0 & \\
\hline
\end{tabular}

Berdasarkan table 3. dapat diketahui tabulasi silang antara variabel kualitas efisiensi dan efektifitas dengan citra RSU dr. Ferdinand Lumbantobing Kota Sibolga, bahwa dari 182 responden yang diamati, terdapat sebanyak 88 orang yang menilai kualitas efisiensi dan efektifitas baik dengan 73 orang $(83,0 \%)$ diantaranya menilai citra RSU dr. Ferdinand Lumbantobing Kota Sibolga baik, sedangkan 15 orang $(17,0 \%)$ sisanya menilai citra RSU $d r$. Ferdinand Lumbantobing Kota Sibolga tidak baik.

Selanjutnya terdapat sebanyak 94 orang yang menilai kualitas efisiensi dan efektifitas tidak baik dengan 57 orang $(53,8 \%)$ diantaranya menilai citra RSU dr. Ferdinand Lumbantobing Kota Sibolga tidak baik, sedangkan 37 orang $(39,4 \%)$ sisanya menilai citra RSU dr. Ferdinand Lumbantobing Kota Sibolga baik. Pada hasil analisis dengan chi square diperoleh nilai $p$ sebesar $0,001(p<\alpha)$, maka dapat disimpulkan bahwa terdapat hubungan yang signifikan antara variabel kualitas efisiensi dan efektifitas dengan citra RSU dr. Ferdinand Lumbantobing Kota Sibolga Tahun 2019.

Berdasarkan tabel 4. dapat diketahui tabulasi silang antara variabel kualitas keselamatan pasien dengan citra RSU $\mathrm{dr}$. 
Ferdinand Lumbantobing Kota Sibolga, bahwa dari 182 responden yang diamati, terdapat sebanyak 90 orang yang menilai kualitas keselamatan pasien baik dengan 60 orang $(66,7 \%)$ diantaranya menilai citra RSU dr.
Ferdinand Lumbantobing Kota Sibolga baik, sedangkan 30 orang $(33,3 \%)$ sisanya menilai citra RSU dr. Ferdinand Lumbantobing Kota Sibolga tidak baik.

Tabel 4.

Tabulasi Silang antara Variabel Kualitas Keselamatan Pasien dengan Citra RSU dr. Ferdinand Lumbantobing Kota Sibolga Tahun 2019

\begin{tabular}{|c|c|c|c|c|c|c|c|}
\hline \multirow{3}{*}{$\begin{array}{c}\text { Kualitas Keselamatan } \\
\text { Pasien }\end{array}$} & \multicolumn{4}{|c|}{ Citra Rumah Sakit } & \multirow{2}{*}{\multicolumn{2}{|c|}{ Total }} & \multirow{3}{*}{$\mathrm{p}$ value } \\
\hline & \multicolumn{2}{|c|}{ Baik } & \multicolumn{2}{|c|}{ Tidak Baik } & & & \\
\hline & $\mathrm{n}$ & $\%$ & $\mathrm{n}$ & $\%$ & $\mathrm{n}$ & $\%$ & \\
\hline Baik & 60 & 66,7 & 30 & 33,3 & 90 & 100,0 & \\
\hline Tidak Baik & 50 & 54,3 & 42 & 45,7 & 92 & 100,0 & 0,023 \\
\hline Total & 110 & 60,4 & 72 & 39,6 & 182 & 100,0 & \\
\hline \multicolumn{4}{|c|}{$\begin{array}{l}\text { Selanjutnya terdapat sebanyak } 92 \text { orang } \\
\text { yang menilai kualitas keselamatan pasien tidak } \\
\text { baik dengan } 50 \text { orang }(54,3 \%) \text { diantaranya } \\
\text { menilai citra RSU dr. Ferdinand Lumbantobing } \\
\text { Kota Sibolga tidak baik, sedangkan } 42 \text { orang } \\
(45,7 \%) \text { lainnya menilai citra RSU dr. Ferdinand }\end{array}$} & \multicolumn{4}{|c|}{$\begin{array}{l}\text { analisis dengan chi square diperoleh nilai } \\
\text { sebesar } 0,023(p<\alpha) \text {, maka dapat disimpulkar } \\
\text { bahwaterdapat hubungan yang signifikar } \\
\text { antara variabel kualitas keselamatan pasier } \\
\text { dengan citra RSU dr. Ferdinand Lumbantobin } \\
\text { Kota Sibolga Tahun } 2019 \text {. }\end{array}$} \\
\hline
\end{tabular}
Lumbantobing Kota Sibolga baik. Pada hasil

Tabel 5.

Tabulasi Silang antara Variabel Kepuasan Pasien dengan Citra RSU dr. Ferdinand Lumbantobing Kota Sibolga Tahun 2019

\begin{tabular}{|c|c|c|c|c|c|c|c|}
\hline \multirow{3}{*}{ Kepuasan Pasien } & \multicolumn{4}{|c|}{ Citra Rumah Sakit } & \multirow{2}{*}{\multicolumn{2}{|c|}{ Total }} & \multirow{3}{*}{$\mathrm{p}$ value } \\
\hline & \multicolumn{2}{|c|}{ Baik } & \multicolumn{2}{|c|}{ Tidak Baik } & & & \\
\hline & $\mathrm{n}$ & $\%$ & $\mathrm{n}$ & $\%$ & $\mathrm{n}$ & $\%$ & \\
\hline Puas & 61 & 60,4 & 40 & 39,6 & 101 & 100,0 & \\
\hline Tidak Puas & 49 & 60,5 & 32 & 39,5 & 81 & 100,0 & 0,001 \\
\hline Total & 110 & 60,4 & 72 & 39,6 & 184 & 100,0 & \\
\hline
\end{tabular}

Berdasarkan tabel 5 dapat diketahui tabulasi silang antara variabel kepuasan pasien dengan citra RSU dr. Ferdinand Lumbantobing Kota Sibolga, bahwa dari 182 responden yang diamati, terdapat sebanyak 101 orang yang menilai puas dengan 61 orang $(60,4 \%)$ diantaranya menilai citra RSU dr. Ferdinand Lumbantobing Kota Sibolga baik, sedangkan 40 orang $(39,6 \%)$ sisanya menilai citra RSU dr. Ferdinand Lumbantobing Kota Sibolga tidak baik.

Selanjutnya terdapat sebanyak 81 orang yang menilai tidak puas dengan 32 orang $(39,5 \%)$ diantaranya menilai citra RSU dr. Ferdinand Lumbantobing Kota Sibolga tidak baik, sedangkan 49 orang $(60,4 \%)$ lainnya menilai citra RSU dr. Ferdinand Lumbantobing Kota Sibolga baik. Pada hasil analisis dengan chi square diperoleh nilai $p$ sebesar $0,001(p<\alpha)$, maka dapat disimpulkan bahwa terdapat hubungan yang signifikan antara variabel kepuasan pasien dengan citra RSU dr. Ferdinand Lumbantobing Kota Sibolga Tahun 2019.

\section{Analisis Multivariat}

Pada analisis multivariat, variabel yang masuk adalah variabel yang pada hasil bivariatnya harus memiliki nilai $p<0,25$. Berdasarkan hasil uji bivariat yang telah dilakukan, diperoleh hasil bahwa hanya variabel kualitas bukti langsung, daya tanggap, empati, kepuasan kontrol dan konfirmasi yang dapat dilakukan analisis multivariat. Adapun variabel 
yang dianggap mempengaruhi dalam model multivariat ini adalah variabel yang mempunyai $\mathrm{p}$ value $<0,05$.

Berdasarkan Tabel 6. dapat diketahui model akhir dari pengaruh variabel kualitas profesi, efisiensi dan efektifitas, keselamatan pasien dan kepuasan pasien memiliki nilai $p<0,05$. Hal ini bermakna bahwa semua variabel independen berpengaruh secara signifikan terhadap variabel dependen. 
Tabel 6.

Model Akhir Multivariat Pengaruh Kualitas Profesi, Efisiensi dan Efektifitas, Keselamatan Pasien dan Kepuasan Pasien Terhadap Citra RSU dr. Ferdinand Lumbantobing Kota Sibolga Tahun 2019

\begin{tabular}{lcccccc}
\hline \multicolumn{1}{c}{ Variabel } & B & S.E & Wald & Df & p value & OR \\
\hline Kualitas Profesi & 0,645 & 0,091 & 4,590 & 1 & 0,001 & 5,203 \\
Kualitas Efisiensi dan Efektifitas & 0,339 & 0,086 & 6,591 & 1 & 0,003 & 1,096 \\
Kualitas Keselamatan Pasien & 0,185 & 0,199 & 3,400 & 1 & 0,001 & 4,103 \\
Kualitas Kepuasan Pasien & 0,142 & 0,071 & 2,921 & 1 & 0,012 & 1,865 \\
\hline
\end{tabular}

Tabel 7.

Pengaruh Keseluruhan Antara Kualitas , Efisiensi dan Efektifitas, Keselamatan Pasien dan Kepuasan Pasien Terhadap Citra RSU dr. Ferdinand Lumbantobing Kota Sibolga Tahun 2019

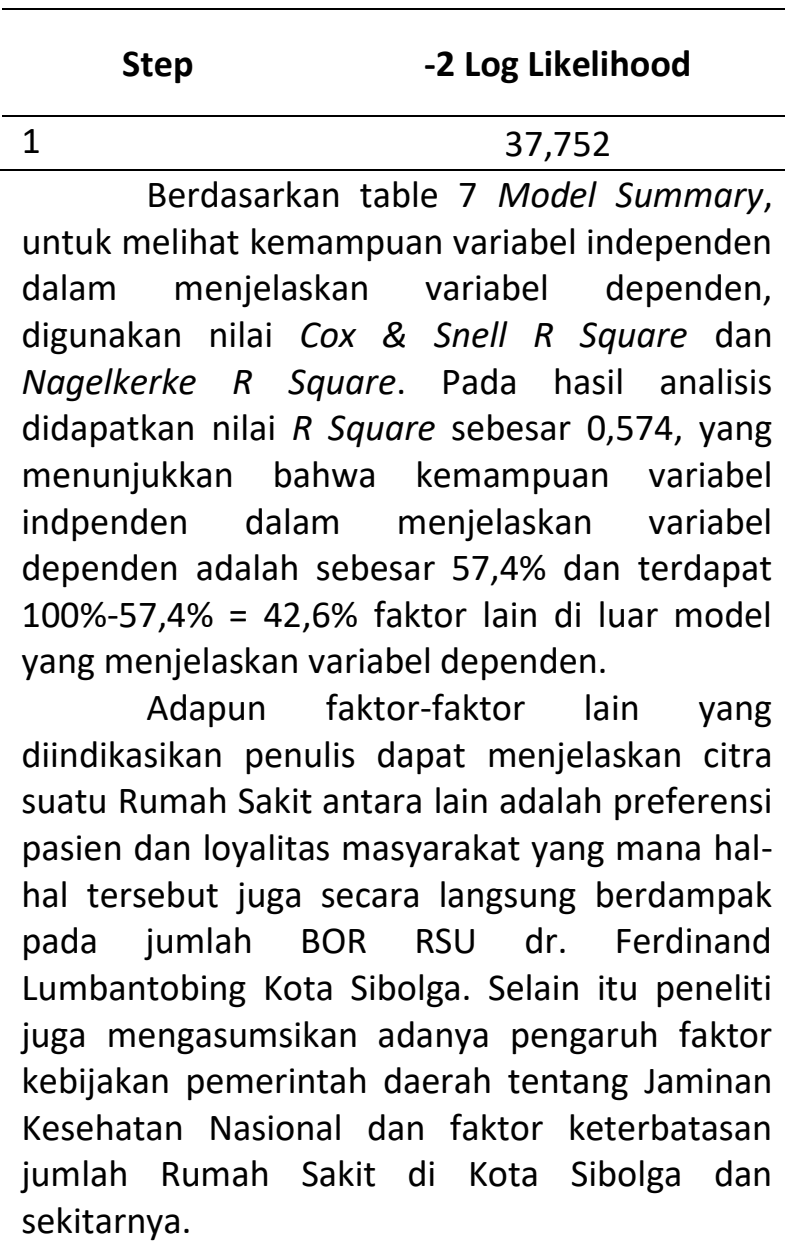

Pengaruh Variabel Kualitas Profesi terhadap Citra RSU dr. Ferdinand Lumbantobing Kota Sibolga Tahun 2019

Berdasarkan hasil analisis multivariat dengan regresi logistik diperoleh variabel kualitas profesi berpengaruh secara signifikan terhadap citra RSU dr. Ferdinand Lumbantobing Kota Sibolga dengan nilai $p<0,05$. Kualitas profesi pada RSU dr. Ferdinand Lumbantobing Kota Sibolga merujuk pada sumber daya
Cox \& Snell R Nagelkerke R

Square Square

$0,574 \quad 0,785$

manusia yang dimiliki oleh organisasi Rumah sakit. Untuk memperoleh informasi tentang ketenagaan (sumber daya manusia) dapat melihat dari kecukupan jumlah tenaga medis dan paramedis terhadap jumlah pasien yang harus terlayani, kesesuaian kualifikasi pendidikan tenaga keperawatan terhadap kebutuhan penyakit pasien, serta pelatihan dan pengembangan.

Hasil penelitian juga didukung oleh hasil wawancara yang dilakukan oleh peneliti terkait kondisi pada instalasi rawat inap berdasarkan ketenagaan/sumber daya manusia, dimana banyak pasien yang menilai kesesuaian jumlah tenaga dengan jumlah pasien tidak seimbang. Hal ini tentu akan mempengaruhi citra pelayanan RSU dr. Ferdinand Lumbantobing Kota Sibolga kepada pasien. Pada uji kompetensi juga dinilai sangat penting diadakan agar tenaga yang direkrut bisa mempunyai kapabilitas sesuai dengan profesinya. Oleh karena itu agar mutu pelayanan kesehatan bisa tercapai sebaiknya perencanaan sumber daya manusia dalam hal tenaga medis lebih ditingkatkan agar dapat terpenuhi kebutuhan pasien di rawat inap.

Sedangkan dalam hal kualifikasi pendidikan RSU dr. Ferdinand Lumbantobing Kota Sibolga tidak mempunyai sistem perekrutan tersendiri untuk para pegawainya. Sebagai RS Pemerintah, RSU dr. Ferdinand Lumbantobing Kota Sibolga hanya menerima quota tenaga yang sudah ada tanpa memilih jenis pendidikan yang dimiliki. Kecuali, untuk 
perekrutan tenaga sukarela, RSU dr. Ferdinand Lumbantobing Kota Sibolga memberikan batasan minimal D3 dan sudah memiliki Surat Izin Perawat (SIP). Namun, khususnya untuk tenaga sukarela RSU dr. Ferdinand Lumbantobing Kota Sibolga tidak bisa merekrut terlalu banyak, karena mereka tenaga yang tidak mendapatkan imbalan financial, dan kalaupun ada mereka harus antri setelah ada penggantian.

Kualifikasi pendidikan merupakan dasar yang penting bagi seorang tenaga medis dan paramedis memberikan pelayanan kepada pasien sesuai dengan kebutuhan penyakitnya, dimana dengan kualifikasi yang ada pasien merasa yakin bahwa diagnosa yang diberikan sesuai dengan penyakitnya. Namun, kualifikasi pendidikan untuk sekarang ini, bukan merupakan hal yang utama dan menjamin keakurata tenaga medis maupun paramedis. ketepatan dalam pemberian pelayanan. Tetapi lebih bersifat individual skill/kompetensi khusus yang dimiliki oleh setiap pribadi tenaga perawat yang ada. Namun, dengan adanya rotasi sedikit banyak tenaga perawat bisa memahami porsi setiap ruang perawatan dan pengetahuan mereka juga bisa semakin bertambah karena mendapatkan bimbingan dari perawat yang sudah lama bekerja. Oleh karena itu sangat diharapkan nantinya bisa dilaksanakan uji kompetensi agar terjadi peningkatan mutu sumber daya manusia (8).

\section{Pengaruh Variabel Kualitas Efisiensi dan Efektifitas terhadap Citra RSU dr. Ferdinand Lumbantobing Kota Sibolga Tahun 2019}

Hasil analisis multivariat dengan regresi logistik diperoleh variabel kualitas efisiensi dan efektifitas berpengaruh secara signifikan terhadap citra RSU dr. Ferdinand Lumbantobing Kota Sibolga dengan nilai $p<0,05$. Analisa data menurut variabel ini merujuk pada bagaimana efisiensi dan efektivitas pelayanan yang diberikan pihak rumah sakit meliputi: kemampuan menyesuaikan diri, produktivitas kerja, kepuasan kerja, pemanfaatan sumber daya dan kemampuan berlaba.

Efisiensi dan efektivitas pelayanan tenaga medis maupun non medis di RSU dr. Ferdinand Lumbantobing Kota Sibolga dapat dilihat dari aspek pelayanan yang diberikan kepada pasien seperti pelayanan administrasi, penunjang, IGD, farmasi dan lainnya. Hasil analisis deskriptif menunjukkan cukup banyak pasien yang menilai pelayanan yang diberikan kurang baik sehingga banyak pasien yang merasa kurang puas.

Hasil ini pun didukung oleh hasil wawancara yang dilakukan dengan beberapa pasien, khususnya terkait pelayanan administrasi di RSU dr. Ferdinand Lumbantobing Kota Sibolga, banyak pasien merasa staff dan pegawai administrasi kurang efektif dalam melaksanakan pekerjaannya. Selain pada pelayanan administrasi, pelayanan yang juga memiliki banyak keluhan adalah pelayanan di Instalasi Gawat Darurat (IGD) RSU dr. Ferdinand Lumbantobing Kota Sibolga. Staff dan pegawai IGD RSU dr. Ferdinand Lumbantobing Kota Sibolga dinilai lambat dalam memahami keluhan apa saja yang dialami pasien. Faktor utama yang dinilai mempengaruhi lambatnya proses penanganan langsung pasien yang datang ke IGD yaitu keterbatasan pegawai yang ada di ruangan IGD RSU dr. Ferdinand Lumbantobing Kota Sibolga.

Permasalahan lainnya terkait efisiensi dan efektivitas pelayanan juga ditemukan peneliti di RSU dr. Ferdinand Lumbantobing Kota Sibolga. Pada dasarnya RSU dr. Ferdinand Lumbantobing Kota Sibolga merupakan rumah sakit tipe $B$, dimana sesuai dengan fungsinya dapat dijadikan rumah sakit rujukan baik dari puskesmas ataupun rumah sakit tipe C. Namun pada faktanya, RSUd r. Ferdinand Lumbantobing Kota Sibolga tidak jarang menolak pasien rujukan atau tidak dapat menangani pasien sesuai dengan semestinya. Seharusnya beberapa rumah sakit tipe $C$ yang berada di sekitar RSU dr. Ferdinand Lumbantobing Kota Sibolga dapat merujuk pasien ke rumah sakit tersebut, namun peneliti menemukan banyak rumah sakit tipe $C$ yang langsung merujuk pasien ke rumah sakit yang ada di Kota Medan dengan alasan lebih baik dan cepat dalam menangani pasien dibandingkan dengan RSU dr. Ferdinand Lumbantobing Kota Sibolga yang memiliki keterbatasan SDM dan peralatan.

Dengan banyaknya permasalahanpermasalahan tesebut dapat menggambarkan bahwa RSU dr. Ferdinand Lumbantobing Kota 
Sibolga masih memiliki kualitas yang kurang baik jika dilihat dari indikator efisiensi dan efektivitas pelayanan, yang tidak dapat memungkiri berdampak pada citra buruk RSU dr. Ferdinand Lumbantobing Kota Sibolga itu sendiri.

\section{Pengaruh Variabel Kualitas Keselamatan Pasien terhadap Citra RSU dr. Ferdinand Lumbantobing Kota Sibolga Tahun 2019}

Hasil analisis multivariat dengan regresi logistik diperoleh variabel kualitas efisiensi dan efektifitas berpengaruh secara signifikan terhadap citra RSU dr. Ferdinand Lumbantobing Kota Sibolga dengan nilai $p<0,05$. Analisa data menurut variabel ini merujuk pada bagaimana pihak rumah sakit dapat menjamin keselamatan pasien yang terkait dengan pemberian pengobatan, peralatan, sarana dan prasarana serta makanan pasien selama menjalani perawatan di RSU dr. Ferdinand Lumbantobing Kota Sibolga.

Berdasarkan hasil observasi di RSU dr. Ferdinand Lumbantobing Kota Sibolga, terdapat beberapa petugas yang belum memahami dengan baik alur pelaporan insiden keselamatan pasien. Petugas tersebut hanya mencatat namun tidak dilaporkan sesuai batas waktu pelaporan yang ditentukan karena masih bingung dengan alur pelaporan insiden keselamatan pasien. Hal tersebut terjadi disebabkan karena petugas dinilai belum sepenuhnya memahami pentingnya pencatatan dan pelaporan dalam upaya keselamatan pasien.

Selain permasalahan terkait pelaporan, peneliti juga menemukan adanya pembiaran atau kurangnya rasa peduli dari tenaga medis RSU dr. Ferdinand Lumbantobing Kota Sibolga terhadap keselamatan pasien. Adanya pembiaran atau kurangnya rasa peduli ini tentunya merugikan pasien bahkan sangat membahayakan kondisi pasien. Baik dokter, perawat maupun pegawai lainnya dinilai kurang memberikan empati terhadap para pasien, sehingga tidak sedikit pasien yang melakukan komplain atas kelalaian dari tenaga medis di RSU dr. Ferdinand Lumbantobing Kota Sibolga. Banyaknya keluhan dan komplain oleh pasien ini sangat berdampak pada penurunan citra RSU dr. Ferdinand Lumbantobing Kota Sibolga itu sendiri, hal ini terlihat dari menurunnya nilai BOR rumah sakit setiap tahunnya.

Pasien tidak sungkan memberikan penilaian positif terkait citra rumah sakit apabila merasa sangat puas dengan empathy dari dokter atau perawat rumah sakit itu sendiri, dimana hal ini dapat diwujudkan dengan menanyakan keluhan pasien, menanggapi keluhan pasien, memperhatikan pasien, dan mengerti apa yang dirasakan pasien. Kartika mendapati adanya pengaruh empati terhadap kesembuhan pasien yang tertuang pada komunikasi antar dokter dan pasien seperti mampu memikirkan apa yang dipikirkan oleh pasien, keperdulian, ketanggapan tindakan, memahami situasi dan kondisi pasien baik fisik maupun perasaannya (6).

Pada dasarnya, keselamatan pasien di rumah sakit adalah suatu susunan sistem yang menjadikan pasien merasa aman dari aspek seperti asasmen risiko, identifikasi dan pengelolaan risiko pasien, pelaporan dan analisis insiden, kemampuan belajar dari insiden dan tindak lanjutnya, serta implementasi solusi untuk meminimalkan timbulnya risiko dan mencegah terjadinya cedera yang disebabkan oleh kesalahan akibat melaksanakan suatu tindakan atau tidak mengambil tindakan yang seharusnya (9).

Salah satu prinsip pelayanan kesehatan adalah menyelamatkan pasien dengan prosedur dan tindakan yang aman dan tidak membahayakan pasien maupun petugas pemberi pelayanan kesehatan. Setiap fasilitas layanan kesehatan harus selalu menjaga keamanan proses pelayanan kesehatannya guna menghindari terjadinya kesalahan medis (medical error) yang bisa berpengaruh terhadap kualitas pelayanan kesehatan (10).

Keselamatan pasien merupakan suatu upaya menjamin segala tindakan dan aktivitas yang berhubungan dengan pasien yang dilakukan oleh petugas kesehatan agar berlangsung dengan aman dan tidak menimbulkan efek atau dampak yang membahayakan bagi pasien melalui serangkaian aktivitas yang telah diatur dalam perundangundangan. Keselamatan pasien menjadi poin penting dalam setiap tindakan medis baik tindakan medis ringan maupun tindakan medis berat. Berdasarkan penelitian 
Maghfiroh \& Rochmah tahun 2007, keselamatan pasien memberikan pengaruh besar terhadap citra, tanggung jawab sosial, moral serta kinerja petugas kesehatan sehingga keselamatan pasien memiliki keterkaitan dengan isu mutu dan citra sebuah pelayanan kesehatan termasuk rumah sakit (11).

Pengaruh Variabel Kepuasan Pasien terhadap Citra RSU dr. Ferdinand Lumbantobing Kota Sibolga Tahun 2019

Berdasarkan hasil analisis multivariat dengan regresi logistik diperoleh variabel kualitas efisiensi dan efektifitas berpengaruh secara signifikan terhadap citra RSU dr. Ferdinand Lumbantobing Kota Sibolga dengan nilai $p<0,05$. Analisa data menurut variabel ini merujuk pada teori kepuasan terhadap kualitas oleh Parasuraman. Teori kepuasan terhadap kualitas atau Servqual terdiri dari beberapa dimensi antara lain dimensi kehandalan, daya tanggap, empati, jaminan dan bukti fisik.

Pada dasarnya kepuasan merupakan suatu penilaian atau bentuk dari persepsi pasien yang menyatakan bahwa suatu layanan telah memberikan tingkat kenikmatan yang sesuai dengan harapan bahkan lebih dari yang diharapkan. Maksud dari tingkat kenikmatan adalah suatu kesesuaian antara kualitas layanan yang dirasakan dari pengalaman menggunakan jasa dengan apa yang diharapkan.

Kepuasan pasien ditentukan oleh persepsi pasien atas performance produk atau jasa dalam memenuhi harapan pasien. Pelanggan merasa puas apabila harapan terpenuhi atau akan sangat terpuaskan jika harapan dari pelanggan terlampaui (3). Pada dasarnya semua usaha manajemen diarahkan untuk mencapai kepuasan pelanggan. Apapun yang dilakukan manajemen tidak ada gunanya jika kepuasan pelanggan tidak tercapai. Jadi fungsi tersebut merupakan kesan dari kinerja dan harapan, jika kinerja dan pelayanan melebihi harapan maka pasien akan merasa puas namun sebaliknya jika kinerja dan pelayanan dibawah harapan maka pasien tidak akan terpuaskan.

Kepuasan pasien menjadi dasar penentu baik tidaknya citra suatu Rumah Sakit. Jika pasien merasa puas dengan kinerja pelayanan Rumah Sakit maka akan terbentuknya sebuah kepuasan pasien. Kepuasan dari pasien akan mendorong pasien datang kembali untuk berobat maupun berkepentingan kepada Rumah Sakit tersebut. Begitupun sebaliknya pasien yang tidak terpuaskan akan meninggalkan dan bahkan tidak akan merekomendasikan kepada yang lain. Karena pada dasarnya pasien hanyalah seseorang yang menerima hasil dari kinerja dan pelayanan dari suatu organisasi maupun instansi, maka hanya merekalah yang bisa mengetahui, merasakan dan menentukan (12).

Beberapa penelitian yang mendukung hasil adalah sebagai berikut, Oktarina, $D$ dengan judul Kualitas Layanan, Dan Citra Merek, Serta Pengaruhnya Terhadap Kepuasan Mahasiswa menyatakan bahwa variabel yang terdiri atas tangibles, empathy, responsiveness, reliability, empathy, responsiveness, assurance dan citra berpengaruh positif terhadap kepuasan mahasiswa di UMM (Universitas Muhammadiyah Metro) (13).

Penelitian terdahulu yang dilakukan Bachtiar yang berjudul Pengaruh Kualitas Pelayanan Dan Kepuasan Pasien Terhadap Citra RSUD Salatiga yang menyatakan bahwa terdapat pengaruh positif dan signifikan kualitas pelayanan yaitu reliability, tangibles, responsiveness, empathy dan assurance terhadap citra RSUD Salatiga (14).

Selanjunya, Nugraha dengan judul penelitian Analisis Pengaruh Citra dan Kualitas Layanan Terhadap Kepuasan Pasien Serta Implikasinya Pada Komunikasi Pemasaran di Rumah Bersalin Fatimah Kota Bandung. Berdasarkan hasil penelitian menunjukkan bahwa kualitas pelayanan (tangibles, empathy, reliability, responsiveness dan assurance) berpengaruh positif dan signifikan terhadap kepuasan pasien (15).

\section{KESIMPULAN}

1. Ada pengaruh kualitas profesi terhadap citra RSU dr. Ferdinand Lumbantobing Kota Sibolga Tahun 2019 ( $\mathrm{p}$ value = $0,001<\alpha$ ).

2. Ada pengaruh kualitas efisiensi dan efektifitas terhadap citra RSU $d r$. Ferdinand Lumbantobing Kota Sibolga Tahun 2019. ( $p$ value $=0,003<\alpha$ ). 
3. Ada pengaruh keselamatan pasien terhadap citra RSU dr. Ferdinand Lumbantobing Kota Sibolga Tahun 2019 ( $p$ value $=0,001<\alpha$ ).

4. Ada pengaruh kepuasan pasien terhadap citra RSU dr. Ferdinand Lumbantobing Kota Sibolga Tahun 2019 ( $p$ value = $0,011<\alpha)$.

\section{UCAPAN TERIMA KASIH}

Peneliti mengucapkan terima kasih kepada enumerator yang banyak memberikan bantuan serta ucapan terima kasih kepada direktur dan perawat RSU dr. Ferdinand Lumbantobing yang telah memberikan izin sebagai tempat pelaksanaan penelitian.

\section{DAFTAR PUSTAKA}

1. Palilati, Alida. Pengaruh Tingkat Kepuasan Terhadap Loyalitas Nasabah Tabungan Perbankan di Wilayah Etnik Bugis. Jurnal Analisis Ekonomi, 2004;1(02):1-15.

2. Irawan, H. 10 Prinsip Kepuasan Pelanggan. Jakarta: PT Elex Media Komputindo; 2003.

3. Kotler Philip, Kevin Lane Keller. Manajemen Pemasaran. Jakarta: Penerbit Prenhallindo; 2009.

4. Hartono, B. Manajemen Pemasaran Untuk Rumah Sakit. Jakarta: Rineka Cipta; 2010.

5. Marzaweny, Dishka. Analisis Kepuasan Pasien sebagai Mediasi Pengaruh Kualitas Pelayanan Kesehatan terhadap Citra Rumah Sakit Umum Daerah (RSUD) Arifin Achmad Pekanbaru. Jurnal Aplikasi Manajemen. September 2012. Vol 10 No 3; hal 566-573.

6. Yulistia. Pengaruh Kualitas Layanan dan Citra Terhadap Kepuasan dan Minat Kembali Untuk Memanfaatkan Pelayanan di Instalasi Rawat Inap Rumah Sakit Umum Daerah Haji Makassar Tahun
2017. Jurnal Ilmiah Kesehatan Diagnosis. 2017. Vol 11 No 4 hal: 429-433

7. Sugiyono. Metode Penelitian Kuantitatif, Kualitatif fan R \& D. Jakarta : Alfabeta. 2014.

8. Nursalam. Manajemen Keperawatan. Jakarta: Salemba Medika; 2011.

9. Firawati AP. Pelaksanaan Program Keselamatan Pasien di RSUD Solok. J Kesehat Masy. 2012;6(2):73-9.

10. Samra, R. et al. How to Monitor Patient Safety in Primary Care? Healthcare Professionals' Views', Journal of the Royal Society of Medicine Open, 7(8), pp. 1-8. doi: 10.1177/2054270416648045.2016.

11. Maghfiroh, L. and Rochmah, T. N.Analisis Kesiapan Puskesmas Demangan Kota Madiun Dalam Menghadapi Akreditasi', Jurnal MKMI, 13(4), pp. 329336.Availableat:http://journal.unhas.ac.id /index.php/mkmi/artile/view/1665.2017.

12. Kartika I.D. Komunikasi Antar Pribadi Perawat dan Tingkat Kepuasan Pasien RSIA Pertiwi: Jurusan Ilmu Komunikasi. FISIP UNHAS. 2013.

13. Oktarina, D. Kualitas layanan, dan citra merek, serta pengaruhnya terhadap kepuasan mahasiswa.tesis. Universitas muhammadyah metro. Bandar lampung. 2016.

14. Bachtiar, Irvan. Pengaruh Kualitas Pelayanan dan Kepuasan Pasien Terhadap Citra RSUD Salatiga. Jurnal Fakultas Ekonomi. Universitas Negeri Semarang; 2015. Vol 05 No 12: hal; 01-15.

15. Nugraha, Nugi Mohammad dkk. Analisis Pengaruh Citra dan Kualitas Layanan Terhadap Kepuasan Pasien Serta Implikasinya Pada Komunikasi Pemasaran di Rumah Bersalin Fatimah Kota Bandung., Jurnal Teknologi dan Manajemen Industri Volume 3 No (1), Februari 2017. 